\title{
PATHWAY ANALYSIS TO DETERMINE FACTORS CONTRIBUTING TO OVERALL QUALITY SCORES IN FOUR BERRY CROPS
}

\author{
Helen COCKERTON*, Maddi BLANCO UNZUETA, Abigail W. JOHNSON, \\ Andrea VADILLO DIEGUEZ, Felicidad FERNÁNDEZ FERNÁNDEZ \\ NIAB EMR, Horticultural Research at East Malling \\ New Road, East Malling, Kent ME19 6BJ, United Kingdom
}

Received: July 2020; Accepted: November 2020

\begin{abstract}
Fruit quality attributes are influenced by environmental, agronomic and genetic factors; both cultivars and growing conditions can vary substantially between UK production and imported fruit. This study aimed to record and dissect the most relevant fruit quality traits for berries imported into the UK in the winter months. Blackberry, blueberry, raspberry and strawberry fruit were imported from 11 countries into a Kent-based packhouse (UK) or purchased from major retailers between December 2018 and March 2019. Multiple fruit quality components were assessed for relative contribution towards a high "overall assessment" fruit quality score. It was found that strawberry and blackberry overall scores were affected by sweetness perception, whereas blueberry and raspberry organoleptics are more complex, with overall scores influenced by flavor perception. Multiple raspberry and strawberry fruit quality traits were found to be associated with genotypic differences, indicating a promising potential for genetic improvement through breeding. By contrast, the study findings suggest that there is less potential for genetic improvement in blueberry, and that the environment may have a large effect on blueberry fruit quality traits.
\end{abstract}

Key words: benchmarking analysis, fruit quality, multiple fruit quality components, overall assessment, organoleptic assessment

\section{INTRODUCTION}

Overall fruit quality is a key selection criteria for breeders. Quality-related attributes (e.g., firmness, color and flavor) are among the most important breeding objectives for commercial berry breeding programs. The increasing demand by growers and consumers for improvements in berry sensory factors has led to fruit quality having equal importance to that of yield and disease resistance for soft fruit breeders. Moreover, unsatisfactory quality of fruit can lead to the rejection of high-yielding cultivars (Brennan \& Graham, 2009). Consumer preference studies can provide guidance on the type of fruit quality improvements required to increase the market share of fruits.
Blueberries have shown a rapidly growing market in the UK. However, improving blueberry flavor and removing seedy, tough, and dry qualities are predicted to increase the blueberry market further (Gilbert et al. 2014). Similarly, it has been proposed that blackberry cultivars must have increased sweetness in order to achieve greater market success (Clark \& Finn 2008), whereas raspberry flavor should be more complex: fruity, sweet and floral, with some acidity (Harrison et al. 1999). It is widely recognized that a balance of acid and sugar is required to achieve a good strawberry flavor (Mitcham 1996), and consumer panels have rated freshness and taste as the most important factors influencing the consumer purchase decision (Ruth \& Rumble 2016). 
Berries are known to improve human health, as they are rich sources of phenolics and antioxidants (Paredes-López et al. 2010; Seeram 2008; Seeram et al. 2006). It may be proposed that improving fruit quality is a way to increase consumption of berries and thus improve human health. Fruit quality encompasses a range of parameters, including visual and organoleptic traits, in addition to non-sensory factors that result in consumer satisfaction (Cardello 1995). Visual traits can influence consumer initial choice at the point of purchase, with higher visual perception leading to greater sales. For example, consumer preference for visual traits has been reported, such as lighter blue color preference in blueberry (Saftner et al. 2008) and color uniformity in raspberry (Villamor et al. 2013). Whereas, perceived flavor as a result of higher organoleptic quality may lead to an increasing brand loyalty and customer return. In order to develop brand loyalty for specific berry cultivars, it is important to increase consumer awareness of linking differences in fruit quality with cultivar names. A case study where brand establishment has been attempted can be found in the brand Zespri, which represents highquality kiwi varieties from New Zealand (Beverland 2001).

Berry breeding programs at the National Institute of Agricultural Botany East Malling Research (NIAB EMR), UK, are all commercially focused and are often developed and/or funded in collaboration with industry partners; hence, fruit quality attributes are crucial in the selection process. In order for breeders to improve the fruit quality of berries, it is important to understand whether available germplasm contains variation in the trait of interest. Here, we quantify the variation in berry quality available in the off-season UK market and determine if a significant proportion of the observed variation is determined by the genotype (here denoted by cultivar). Finally, we seek to determine which of the components assessed contribute to a high "overall assessment" fruit quality score.

\section{MATERIALS AND METHODS}

A total of 610 punnets of fruit were sampled 74 blackberry ( 9 cultivars), 164 blueberry ( 36 cultivars), 185 raspberry (30 cultivars) and 187 strawberries (36 cultivars) - imported from 11 countries into a Kent packhouse (UK) or purchased from one of five major retailers. The berries were evaluated between December 2018 and March 2019 (Supplementary Table 1). Only berries of known cultivars were included in the assessment. Data on grower, organic status, country of origin and range (saver, standard or luxury) were recorded, when listed on the packaging. Best before date and the date of assessment were recorded and used to calculate the number of days before best. Whole punnet assessments followed the procedures used in Rubus (raspberry and blackberry) and strawberry breeding programs based at the research institute in NIAB EMR, UK, details of which can be found in the "Fruit quality traits" section below. Blueberry fruit quality assessment criteria were developed as part of this study. Traits (detailed below) were scored on a scale or as binary traits, as appropriate. Organoleptic assessment was conducted on $>4$ berries per punnet, or $>8$ for blueberries, and scores assigned through consensus of two trained assistant breeders. Crackers and water were used as palate cleansers between berries, and regular breaks were taken to avoid palate fatigue. Data were collected using the Field Book application (Rife \& Poland 2014).

\section{Fruit quality traits}

Fruit quality traits were assessed across the whole punnets on nine point scales flavor (very poor -1 , excellent -9 ), skin strength (very fragile -1 , very strong -9 ), texture (very poor -1 , excellent 9), sweetness perception (none - 1, very high sweetness -9 ), acidity perception (none -1 , very high acidity -9), general appearance (very poor - 1, excellent -9), uniformity (completely irregular -1 , complete uniformity around the central axis -9) and overall assessment (very poor -1 , excellent -9 ). The weight of ten fruit, or 20 for blueberry, was taken. 
Strawberry-specific traits included total soluble solids (Brix), which was measured using a refractometer (Atago PAL 1) and skin color (pale orange - 1, wine red - 9). Raspberry-specific traits included redness (pale orange -1 , wine red -9 ). Blueberryspecific traits included firmness (very soft -1 , very hard - 9). Blackberry traits included brightness (very dull -1 , very bright -9 ).

\section{Statistical methods}

The "Ime4" R package version 1.1-21 (Bates et al. 2015) was used to generate mixed models treating berry range, day before best, cultivar, supermarket and country of origin as random variates. A Wald test was used to compare linear mixed models to determine if variates were significantly associated with quality metrics. For each quality metric, a model was built whereby the fruit trait was treated as a fixed effect and range, cultivar, supermarket, best before date and country as random effects; this model was compared to a model without the specific tested descriptor. The "stats" R base package (R Core Team 2018) was used to conduct principal component analysis (PCA) on all fruit quality metrics; traits were scaled for analysis; and biplots were produced in the "ggfortify" R package version 0.4.11 (Tang et al. 2016). The "semPlot" $\mathrm{R}$ package version 1.1.2 (Epskamp 2019) was used to conduct pathway analysis, which allowed identification of the components influencing high overall fruit quality scores. $\mathrm{R}$ version 3.5.1 was used for analysis (R Core Team 2018).

\section{RESULTS AND DISCUSSION}

Associations between fruit quality traits and berry range, cultivar, supermarket of origin, date before best and country of origin were assessed. The mixed model analysis controlled for confounding variation in all other variables. Details of significant associations between traits can be found in Table 1 . Cultivar variation is of high interest for the breeder, as this indicates the relative potential to breed for particular traits. The experiment sought to determine whether a significant proportion of the observed variation in fruit quality is controlled by genotypic rather than environmental variation.
Cultivar was found to influence multiple raspberry fruit quality traits: sweetness perception, acidity perception, general appearance and overall score. This indicates the importance of cultivar choice in fruit quality. Similarly, strawberry cultivar was found to influence the sweetness perception and overall assessment of the fruit. Blueberry cultivar was found to influence fruit firmness and overall assessment of the fruit. By contrast, blackberry cultivar was not significantly associated with differences in fruit quality traits, indicating that genetic variation does not play a large role in variation observed in this study. However, this may be due to the market dominance of 'Tupi' and the low number of cultivars represented in this analysis. Sample biasing was addressed through permutation tests to remove random subsets of 'Tupi' observations for re-testing; trends reported in Table 1 were not altered. In fact, genotype has been shown to have a greater effect on blackberry fruit quality than environmental effects (Reyes-Carmona et al. 2005). Country of origin was significantly associated with acidity perception for blackberries and blueberries. It is hypothesized that the significant association between country and acidity may be due to the influence of photoperiod on metabolite production. Light intensity and spectrum quality are known to affect flavonoid production (Jenkins 2008).

PCA was used to indicate the greatest varying components present across the assessed berries (Fig. 1). Average scores for each trait by crop can be found in Supplementary Table 2. After scaling traits, principal component 1 (PC1) explained over $32 \%$ of the variation present in the assessed fruit for all berries in each separate analysis. PC1 correlated with multiple factors, as evident in Figure 1; however, for each berry, the largest varying component was overall score for strawberry $(r=0.46)$, raspberry $(r=0.55)$, blueberry $(r=0.58)$ and blackberry $(\mathrm{r}=0.56)$. Principal component 2 correlated with acidity perception for both blackberry $(r=0.62)$ and raspberry $(r=0.65)$, which explained 22 and $16.5 \%$ of the variation, respectively. By contrast, principal component 2 correlated with mass of fruit for both strawberry $(r=0.42)$ and blueberry $(r=-0.55)$, which explained 17.3 and $23.5 \%$ of the variation, respectively. 
Pathway analysis provides a tool to dissect the components that a breeder is subconsciously prioritizing when assessing the overall value of a given fruit. The analysis indicated that a high overall score for strawberry fruits was composed of prioritizing general appearance $(r=0.45 ; p<0.001)$, with additional traits showing a weaker but significant impact; texture $(r=0.26$; $p<0.001)$ and sweetness $(r=0.22 ; p=0.001 ;$ Fig. 2$)$.

Table 1. Significance values associated with berry range, cultivar, supermarket of origin, date before best and country of origin with fruit quality attributes. $P$-values associated with a chi ${ }^{2}$ test comparing two mixed models with and without target variable. NS denotes non-significant comparisons

\begin{tabular}{|c|c|c|c|c|c|c|c|}
\hline Strawberry & Flavor & Sweetness & Acidity & Overall & Texture & Appearance & Brix \\
\hline Range & NS & NS & NS & NS & NS & NS & NS \\
\hline Cultivar & NS & 0.040 & NS & 0.012 & NS & NS & NS \\
\hline Supermarket & NS & NS & NS & NS & NS & 0.093 & NS \\
\hline Date before best & NS & NS & NS & 0.000 & 0.098 & 0.021 & NS \\
\hline Country & NS & NS & NS & NS & NS & NS & NS \\
\hline Blueberry & Flavor & Sweetness & Acidity & Overall & Texture & Appearance & Firmness \\
\hline Range & NS & NS & NS & NS & NS & NS & NS \\
\hline Cultivar & NS & NS & NS & 0.028 & NS & NS & 0.006 \\
\hline Supermarket & NS & NS & NS & NS & NS & NS & NS \\
\hline Date before best & NS & NS & 0.016 & NS & NS & NS & NS \\
\hline Country & NS & NS & 0.000 & NS & NS & NS & 0.029 \\
\hline Raspberry & Flavor & Sweetness & Acidity & Overall & Texture & Appearance & Redness \\
\hline Range & NS & NS & NS & NS & NS & NS & NS \\
\hline Cultivar & NS & 0.014 & 0.001 & 0.009 & NS & 0.002 & NS \\
\hline Supermarket & NS & NS & NS & NS & NS & 0.068 & 0.032 \\
\hline Date before best & NS & NS & NS & NS & NS & NS & NS \\
\hline Country & NS & NS & NS & NS & NS & NS & 0.072 \\
\hline Blackberry & Flavor & Sweetness & Acidity & Overall & Texture & Appearance & Brightness \\
\hline Cultivar & NS & NS & NS & NS & NS & NS & NS \\
\hline Supermarket & NS & NS & NS & NS & NS & NS & NS \\
\hline Date before best & NS & NS & NS & NS & NS & NS & 0.048 \\
\hline Country & NS & 0.001 & 0.001 & NS & NS & NS & NS \\
\hline
\end{tabular}



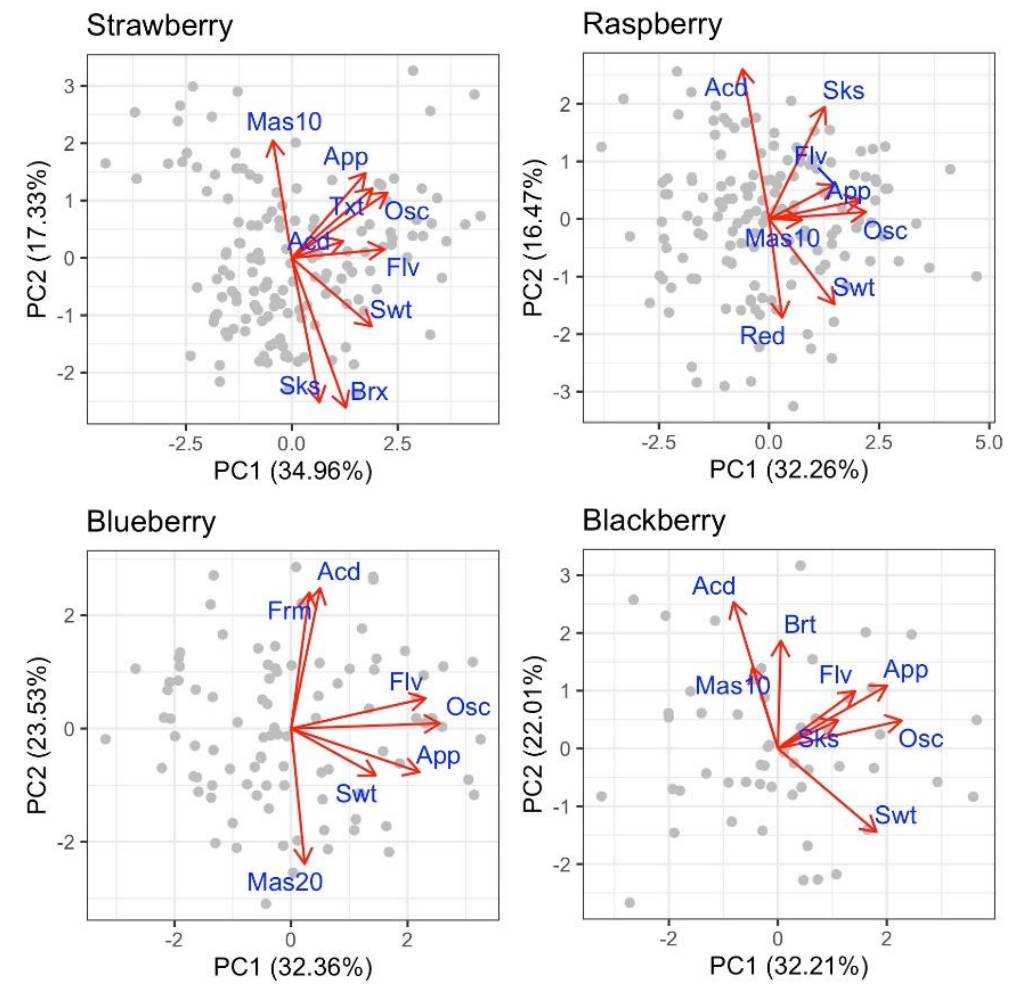

Figure 1. Biplots detailing variation in the fruit quality data. Trait names denoted as follows: Osc - overall score, App appearance, Swt - sweetness perception, Acd - acid perception, Mas10 - mass of 10 berries, Mas 20 - mass of 20 berries, Flv - flavor score, Txt - texture, Col - color, Sks - skin strength, Red - redness, Brt - brightness, Brx - Brix/total soluble sugars

Strawberry was the only berry that showed a significant contribution of texture to the overall score. Previous studies have found that sweetness and complex flavors were the most important attributes of strawberry (Colquhoun et al. 2012). However, they also found that the demographic strongly influenced strawberry preference, and that the "perfect strawberry" could not be defined (Colquhoun et al. 2012). The negative correlation between fruit color and sweetness in strawberry may be due to the subconscious impact of color on sweetness perception, as found in previous studies (Johnson et al. 1983). Raspberry overall assessment was strongly influenced by general appearance $(\mathrm{r}=0.61 ; \mathrm{p}<0.001)$ and weakly influenced by flavor $(r=0.28 ; p<0.001$, Fig. 3$)$. The importance of color and flavor has also been determined in additional studies where aroma and flavor components were further dissected into "green", "floral" and "raspberry" notes (Villamor et al. 2013). Blackberry overall score was influenced by general appearance $(\mathrm{r}=0.61 ; \mathrm{p}<0.001)$, sweetness $(\mathrm{r}=0.51 ; \mathrm{p}<0.001)$, and, to a lesser degree, acidity perception $(\mathrm{r}=0.26 ; \mathrm{p}=0.016)$ and flavor $(\mathrm{r}=0.15$; $\mathrm{p}=0.024$, Fig. 4); indeed, increasing sweetness has been reported as a key requirement for blackberry market expansion (Clark \& Finn 2008), and a clear consumer preference for low acidity and high sugar has been observed for fresh blackberry fruit (Naumann \& Wittenburg 1980). Blueberry overall assessment was influenced by general appearance $(r=0.42 ; \mathrm{p}<0.001)$ and flavor $(\mathrm{r}=0.40$; $\mathrm{p}<0.001$, Fig. 5).

Through understanding the most important fruit quality traits influencing the final overall cultivar score, breeders can streamline the seedling analysis process and focus on traits that have the largest impact on the overall score. These results can assist decision support in streamlining and thus reducing the time required for phenotyping a training population as part of implementing genomic selection and prediction. 


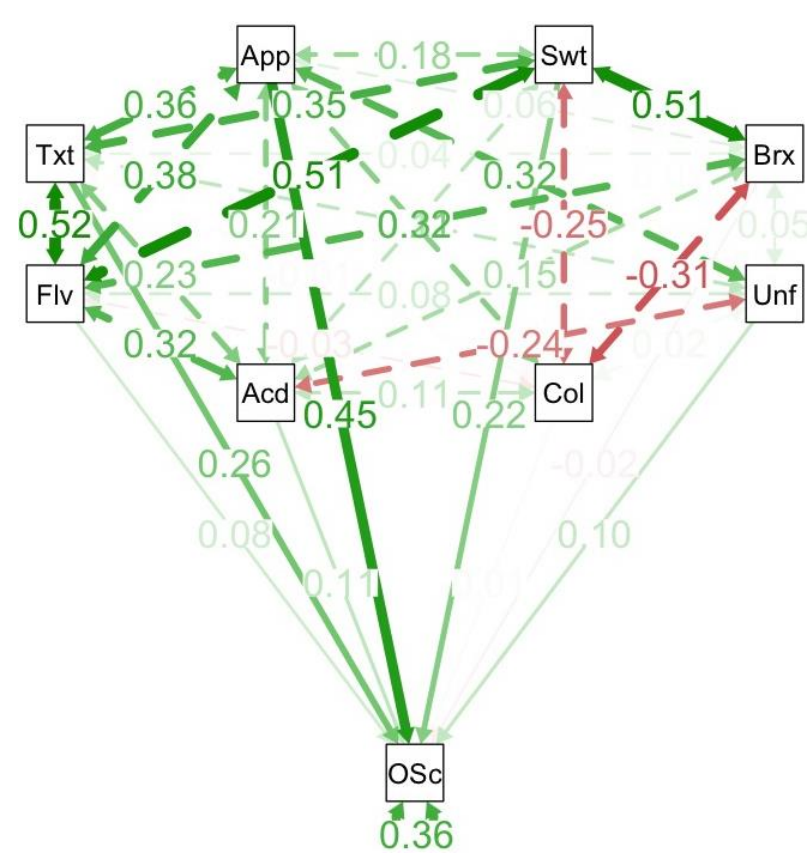

Figure 2. Pathway analysis influence of different traits on the overall fruit quality score (Osc) in strawberry. Weight of links represents relative association between traits. Solid lines show links between overall score (Osc) and other traits, whereas dashed lines show links between other traits. App - appearance, Swt - Sweetness perception, Acd - acid perception, Flv - flavor score, Txt - texture, Col - color, Unf - Uniformity. Numbers are correlation coefficients

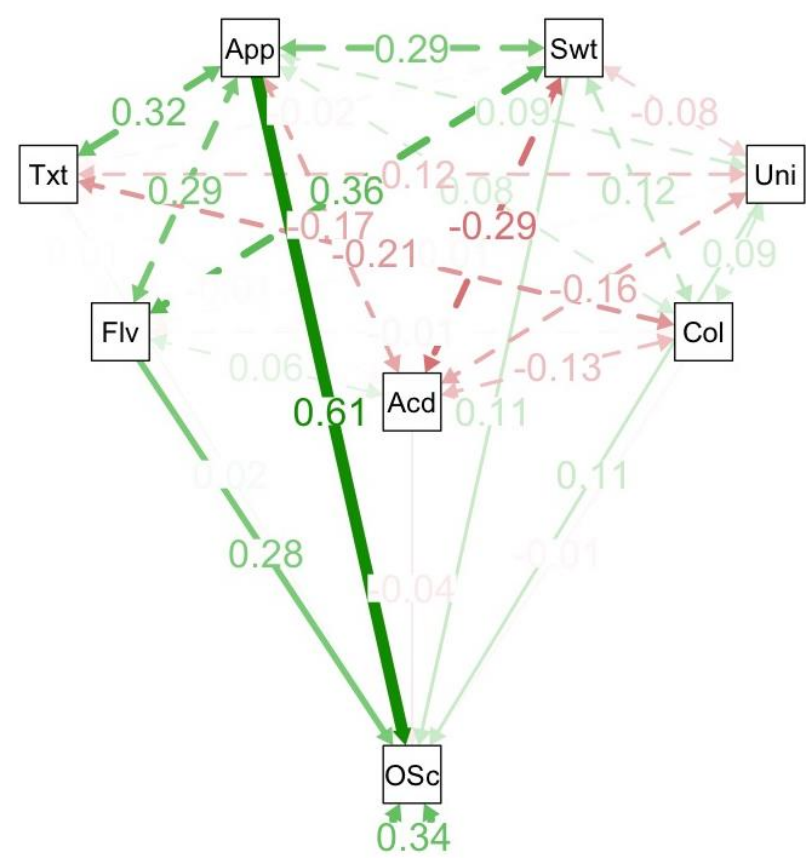

Figure 3. Pathway analysis influence of different traits on the overall fruit quality score (Osc) in raspberry. Note: See Fig. 1

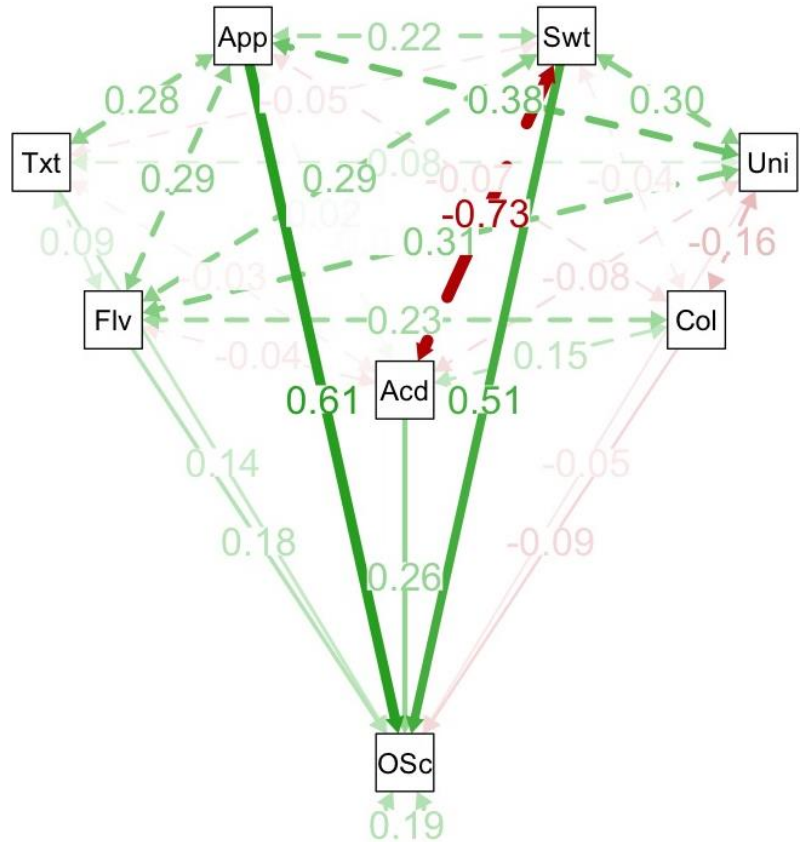

Figure 4. Pathway analysis influence of different traits on the overall fruit quality score (Osc) in blackberry. Note: See Fig. 1

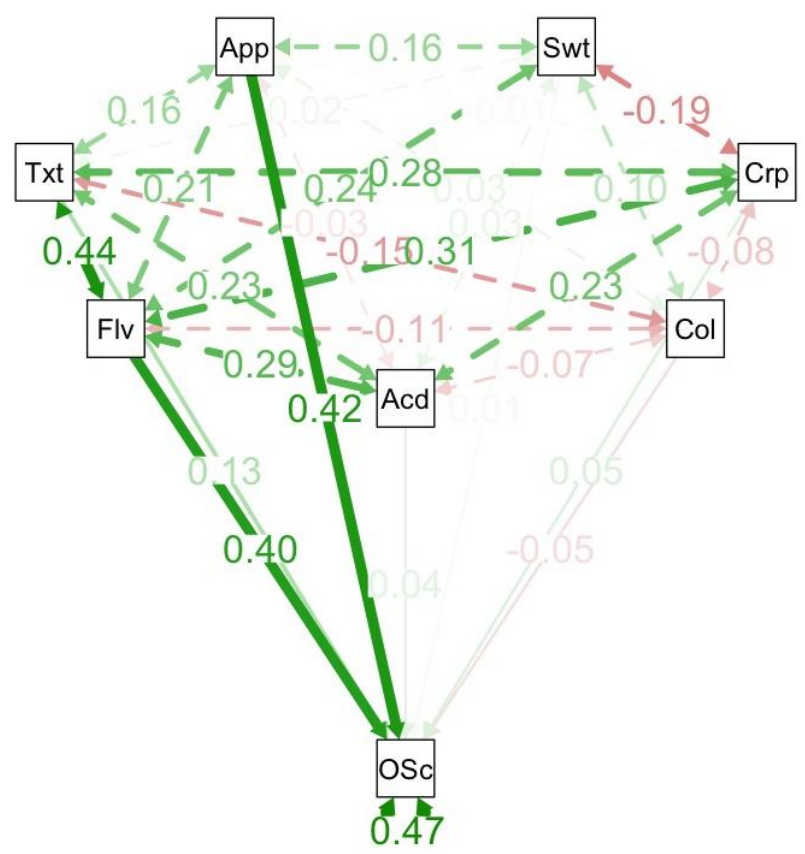

Figure 5. Pathway analysis influence of different traits on the overall fruit quality score (Osc) in blueberry. Weight of links represents relative association between traits. Solid lines show links between overall score (Osc) and other traits, whereas dashed lines show links between other traits. App - appearance, Swt - Sweetness perception, Acd - acid perception, Flv - flavor score, Txt - texture, Col - color, Crp - Crispness. Numbers are correlation coefficients 


\section{CONCLUSIONS}

In spite of the development of objective fruit quality methods, the subjective assessment of fruit quality remains an important component of breeding programs. Our findings suggest that multiple raspberry and strawberry fruit quality traits can be influenced through genetic improvement. Less potential for genetic improvement was found in blueberry, and as such, it is proposed that the environment may have a large effect on blueberry fruit quality traits. While breeders assign each seedling on the overall fruit quality score, this analysis has allowed the dissection of the relative importance of visual and organoleptic traits on overall fruit quality scores and concludes that all berries were influenced by general appearance. Furthermore, raspberry and blueberry were influenced by flavor, whereas blackberry and strawberry were influenced by sweetness, and strawberry was influenced by texture.

\section{Acknowledgments}

The authors would like to acknowledge support from the East Malling Rubus Breeding Consortium, the strawberry Soloberry breeding program as well as WB Chambers' packhouse. MBU and AVD gratefully acknowledge the funding from the Novia Salcedo Foundation for their internships at NIAB EMR. HC was funded through Biotechnology and Biological Sciences Research Council (BBSRC) BB/M01200X/2, BB/P005039/1.

\section{REFERENCES}

Bates D., Mächler M., Bolker B.M., Walker S.C. 2015. Fitting linear mixed-effects models using lme4. Journal of Statistical Software 67(1): 1-48. DOI 10.18637/jss.v067.i01.

Beverland M. 2001. Creating value through brands: the ZESPRI $^{\mathrm{TM}}$ kiwi fruit case. British Food Journal 103: 383-399. DOI: 10.1108/00070700110400389.

Brennan R., Graham J. 2009. Improving fruit quality in Rubus and Ribes through breeding. Functional Plant Science and Biotechnology 3: 22-29.
Cardello A.V. 1995. Food quality: Relativity, context and consumer expectations. Food Quality and Preference 6: 163-170. DOI: 10.1016/09503293(94)00039-x.

Clark J.R., Finn C.E. 2008. New trends in blackberry breeding. Acta Horticulturae 777: 41-48. DOI: 10.17660/actahortic.2008.777.2.

Colquhoun T.A., Levin L.A., Moskowitz H.R. Whitaker V.M., Clark D.G., Folta K.M. 2012. Framing the perfect strawberry: An exercise in consumerassisted selection of fruit crops. Journal of Berry Research 2: 45-61. DOI: 10.3233/jbr-2011-027.

Epskamp S. 2019. Package 'semPlot'. Path diagrams and visual analysis of various SEM packages' output.

Gilbert J.L., Olmstead J.W., Colquhoun T.A., Levin L.A., Clark D.G., Moskowitz H.R. 2014. Consumerassisted selection of blueberry fruit quality traits. HortScience 49: 864-873. DOI: 10.21273/hortsci.49.7.864.

Harrison R.E., Brennan R.M., Hunter E.A., Morel S., Muir D.D. 1999. Genotypic, environmental and processing effects on the sensory character of Rubus and Ribes. Acta Horticulturae 505: 25-32. DOI: 10.17660/actahortic.1999.505.1.

Jenkins G.I. 2008. Environmental regulation of flavonoid biosynthesis. In: Givens I., Baxter S., Minihane A.M., Shaw E. (eds.), Health benefits of organic food. Effects of the environment. CABI, Wallingford, UK, pp. 240-262. DOI: 10.1079/9781845934590.0240.

Johnson J.L., Dzendolet E., Clydesdale F.M. 1983. Psychophysical relationship between sweetness and redness in strawberry-flavored drinks. Journal of Food Protection 46: 21-25. DOI: 10.4315/0362028x-46.1.21.

Mitcham B. 1996. Quality assurance for strawberries: A case study. Perishables Handling Newsletter 85: 6-9.

Naumann W.D., Wittenburg U. 1980. Anthocyanins, soluble solids, and titratable acidity in blackberries as influenced by preharvest temperatures. Acta Horticulturae 112: 183-190. DOI: 10.17660/actahortic.1980.112.25. 
Paredes-López O., Cervantes-Ceja M.L., Vigna-Pérez M., Hernández-Pérez T. 2010. Berries: Improving human health and healthy aging, and promoting quality life - A review. Plant Foods for Human Nutrition 65: 299-308. DOI: 10.1007/s11130-010-0177-1.

Reyes-Carmona J., Yousef G.G., Martínez-Peniche R.A., Lila M.A. 2005. Antioxidant capacity of fruit extracts of blackberry (Rubus sp.) produced in different climatic regions. Journal of Food Science 70: 497503. DOI: 10.1111/j.1365-2621.2005.tb11498.x.

Rife T.W., Poland J.A. 2014. Field Book: An open-source application for field data collection on Android. Crop Science 54: 1624-1627. DOI: 10.2135/cropsci2013.08.0579.

Ruth T.K., Rumble J.N. 2016. Branding the berries: Consumers' strawberry purchasing intent and their attitude toward Florida strawberries. Journal of Applied Communications 100: 28-43. DOI: 10.4148/1051-0834.1028.

Saftner R., Polashock J., Ehlenfeldt M., Vinyard B. 2008. Instrumental and sensory quality characteristics of blueberry fruit from twelve cultivars. Postharvest Biology and Technology 49: 19-26. DOI: 10.1016/j.postharvbio.2008.01.008.
Seeram N.P. 2008. Berry fruits: Compositional elements, biochemical activities, and the impact of their intake on human health, performance, and disease. Journal of Agricultural and Food Chemistry 56: 627-629. DOI: 10.1021/jf071988k.

Seeram N.P., Adams L.S., Zhang Y., Lee R., Sand D., Scheuller H.S., Heber D. 2006. Blackberry, black raspberry, blueberry, cranberry, red raspberry, and strawberry extracts inhibit growth and stimulate apoptosis of human cancer cells in vitro. Journal of Agricultural and Food Chemistry 54: 9329-9339. DOI: $10.1021 / \mathrm{jf061750g}$.

Tang Y., Horikoshi M., Li W. 2016. ggfortify: Unified interface to visualize statistical results of popular $\mathrm{R}$ packages. $\mathrm{R}$ Journal 8: 474-485. DOI: $10.1021 / \mathrm{jf06} 1750 \mathrm{~g}$.

R Core Team 2018. R: A language and environment for statistical computing. The R Foundation for Statistical Computing, Vienna, Austria. www.r-project.org

Villamor R.R., Daniels C.H., Moore P.P., Ross C.F. 2013. Preference mapping of frozen and fresh raspberries. Journal of Food Science 78: 911-919. DOI: 10.1111/1750-3841.12125. 